\title{
Microstructure and Magnetic Properties of NdFeB Films through Nd Surface Diffusion Process
}

\author{
Wenfeng Liu, Mingang Zhang, Kewei Zhang, and Yuesheng Chai \\ School of Materials Science and Engineering, Institute of Advanced Materials, Taiyuan University of Science and Technology, \\ Taiyuan 030024, China \\ Correspondence should be addressed to Mingang Zhang; mgzhang@163.com
}

Received 4 October 2016; Revised 5 December 2016; Accepted 19 December 2016; Published 18 January 2017

Academic Editor: Jingsheng Chen

Copyright (C) 2017 Wenfeng Liu et al. This is an open access article distributed under the Creative Commons Attribution License, which permits unrestricted use, distribution, and reproduction in any medium, provided the original work is properly cited.

$\mathrm{Ta} / \mathrm{Nd} / \mathrm{NdFeB} / \mathrm{Nd} / \mathrm{Ta}$ films were deposited by magnetron sputtering on $\mathrm{Si}(100)$ substrates and subsequently annealed for $30 \mathrm{~min}$ at $923 \mathrm{~K}$ in vacuum. It was found that the microstructure and magnetic properties of $\mathrm{Ta} / \mathrm{Nd} / \mathrm{NdFeB} / \mathrm{Nd} / \mathrm{Ta}$ films strongly depend on the NdFeB layer thickness. With $\mathrm{NdFeB}$ layer thickness increasing, both the grain size and the strain firstly reduce and then increase. When $\mathrm{NdFeB}$ layer thickness is $750 \mathrm{~nm}$, the strain reaches the minimum value. Meanwhile, both the in-plane and perpendicular coercivities firstly drastically increase and then slowly decrease with NdFeB layer thickness increasing. The highest in-plane and perpendicular coercivities can be obtained at NdFeB layer thickness of $750 \mathrm{~nm}$, which are $21.2 \mathrm{kOe}$ and $19.5 \mathrm{kOe}$, respectively. In addition, the high remanence ratio (remanent magnetization/saturation magnetization) of 0.87 can also be achieved in $\mathrm{Ta} / \mathrm{Nd} / \mathrm{NdFeB}(750 \mathrm{~nm}) / \mathrm{Nd} / \mathrm{Ta}$ film.

\section{Introduction}

$\mathrm{NdFeB}$ permanent magnetic films have drawn extensive attention due to their excellent hard magnetic properties and potential applications in microelectromechanical system (MEMS), micromagnetic devices, and magnetic recording media [1-6]. The relatively low coercivity and poor thermal stability are the practical obstacle for applications of $\mathrm{NdFeB}$ films. One major approach to improve the properties is to increase the coercivity at the room temperature, which can suppress demagnetization at a higher operating temperature.

To increase the coercivity of $\mathrm{NdFeB}$ films, many researches have been reported. Fukagawa et al. reported that after sputtering $\mathrm{Nd}$ metal to the surface of $\mathrm{NdFeB}$ magnet and subsequent annealing an fcc interfacial phase was formed between the surface grains and the Nd layer, resulting in the recovery of surface coercivity [7]. Kim et al. reported that by $\mathrm{Nd}$ element diffusing from $\mathrm{Nd}$ layer into $\mathrm{NdFeB}$ layer high coercivity was achieved at the thickness ratio of $\mathrm{Nd} / \mathrm{NdFeB} \geq 1$. However, a rather low content of $\mathrm{NdFeB}$ hard magnetic phase existed in the films [8]. Li et al. reported that the coercivity of $[\mathrm{NdFeB} / \mathrm{Nd}]_{4}$ films was fairly increased because that $\mathrm{Nd}$ element effectively diffused [9].
In this work, $\mathrm{Ta} / \mathrm{Nd} / \mathrm{NdFeB} / \mathrm{Nd} / \mathrm{Ta}$ films were prepared on $\mathrm{Si}$ (100) substrates by magnetron sputtering. The effect of the $\mathrm{NdFeB}$ layer thickness on the microstructure and magnetic properties of $\mathrm{Ta} / \mathrm{Nd} / \mathrm{NdFeB} / \mathrm{Nd} / \mathrm{Ta}$ films was systematically investigated. The high in-plane and perpendicular coercivities can be obtained in Ta/Nd/NdFeB $(750 \mathrm{~nm}) / \mathrm{Nd} / \mathrm{Ta}$ film, which are $21.2 \mathrm{kOe}$ and $19.5 \mathrm{kOe}$, respectively. The high remanence ratio of 0.87 can also be achieved in the film.

\section{Experimental Procedure}

$\mathrm{Ta} / \mathrm{Nd} / \mathrm{NdFeB} / \mathrm{Nd} / \mathrm{Ta}$ films were prepared by FJL560II ultrahigh vacuum magnetron sputtering system on $\mathrm{Si}$ (100) substrates. Here, Nd layer thickness was fixed at $250 \mathrm{~nm}$. A Ta underlayer of $60 \mathrm{~nm}$ and Ta coverlayer of $60 \mathrm{~nm}$ were used to suppress the oxidation of NdFeB films. Pure $\mathrm{Nd}$ (99.9\%) and $\mathrm{Ta}(99.95 \%)$ targets were used. The target for NdFeB layer was a commercial $\mathrm{N} 33 \mathrm{H} \mathrm{NdFeB}$ sintered target attached to B-chips. The base pressure of the deposition chamber was $2.0 \times 10^{-4} \mathrm{~Pa}$ and high purity Ar gas was introduced during sputtering. The composition of $\mathrm{NdFeB}$ layer was determined to be $\mathrm{Nd}_{10.73} \mathrm{Fe}_{84.01} \mathrm{~B}_{5.26}$ by a Thermo System 7 energy dispersive spectrometer (EDS). The as-deposited 


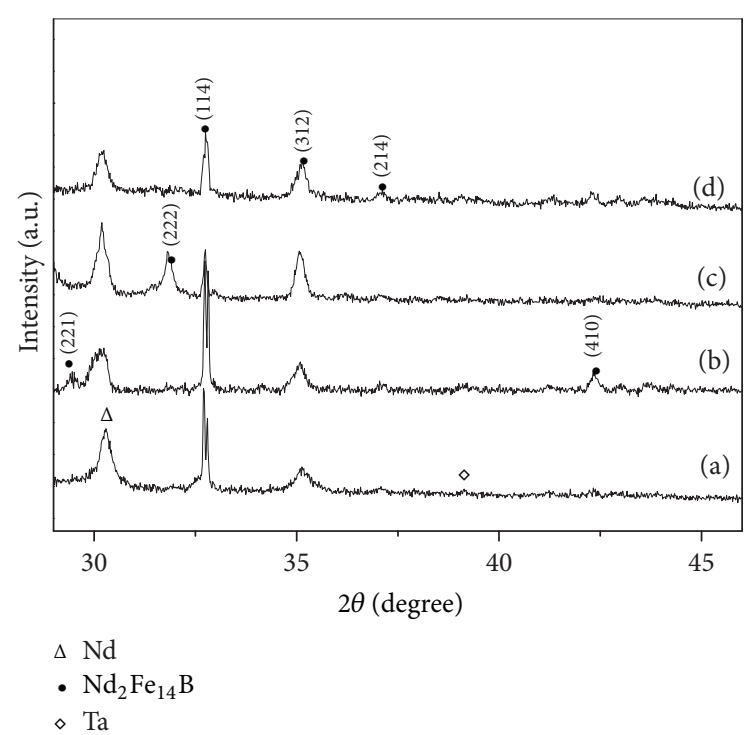

FIgURE 1: XRD patterns of Ta/Nd/NdFeB $(x \mathrm{~nm}) / \mathrm{Nd} / \mathrm{Ta}((\mathrm{a}) x=$ 450; (b) $x=600$; (c) $x=750$; (d) $x=900$ ) films.

films were subsequently annealed for $30 \mathrm{~min}$ at $923 \mathrm{~K}$ in vacuum.

The structure of the films was analyzed by Bruker-D8 Xray diffraction (XRD) with $\mathrm{Cu} \mathrm{K} \alpha$ radiation. The thickness was characterized by a JSM-7001F field emission scanning electron microscope (FE-SEM). The magnetic properties were measured by a Quantum Design vibrating sample magnetometer (VSM) with a maximum applied field of $30 \mathrm{kOe}$.

\section{Results and Discussion}

Figure 1 shows the XRD patterns of $\mathrm{Ta} / \mathrm{Nd} / \mathrm{NdFeB}(x \mathrm{~nm}) /$ $\mathrm{Nd} / \mathrm{Ta}(x=450,600,750,900)$ films. The prominent characterization peaks of (222), (114), (312), and (410) can be obviously seen in the XRD patterns, indicating the formation of tetragonal $\mathrm{Nd}_{2} \mathrm{Fe}_{14} \mathrm{~B}$ phase. In addition to the abovementioned peaks, $\mathrm{Nd}$ peaks are also clearly observed in the XRD patterns, due to the existence of Nd layer.

XRD can be utilized to evaluate peak broadening with crystallite size and lattice strain due to dislocation [10]. Williamson-Hall (W-H) analysis [11] considers that the contributions to line broadening of the crystallite size and lattice strain are independent of each other and both have a Cauchylike profile; the final line breadth is the sum

$$
\begin{aligned}
& \beta_{h k l}=\beta_{S}+\beta_{D}, \\
& \beta_{h k l}=\left(\frac{k \lambda}{D \cos \theta}\right)+(4 \varepsilon \tan \theta) .
\end{aligned}
$$

Rearranging (2), we get

$$
\beta_{h k l} \cos \theta=\left(\frac{k \lambda}{D}\right)+(4 \varepsilon \sin \theta),
$$

where $D$ is the average grain size, $K$ is the shape factor (0.9), $\lambda$ is the wavelength of $\mathrm{Cuk}_{\alpha}$ radiation, and $\varepsilon$ is the strain. The strain was assumed to be uniform in all crystallographic directions. As shown in Figure $2, \beta \cos \theta$ was plotted with respect to $\sin \theta$ for the $\mathrm{Nd}_{2} \mathrm{Fe}_{14} \mathrm{~B}$ peaks of $\mathrm{Ta} / \mathrm{Nd} / \mathrm{NdFeB} / \mathrm{Nd} / \mathrm{Ta}$ films. The grain size and strain were calculated from the $y$-intercept and slope of the fitted line, respectively. Figure 3 shows the variation of the grain size and strain with $\mathrm{NdFeB}$ layer thickness in $\mathrm{Ta} / \mathrm{Nd} / \mathrm{NdFeB} / \mathrm{Nd} / \mathrm{Ta}$ films. With NdFeB layer thickness increasing from $450 \mathrm{~nm}$ to $900 \mathrm{~nm}$, both the grain size and the strain firstly reduce and then increase. When the NdFeB layer thickness is $750 \mathrm{~nm}$, the strain reaches the minimum value, which is equal to 0.0016 .

Figure 4 shows the dependence of the coercivity on the $\mathrm{NdFeB}$ layer thickness in $\mathrm{Ta} / \mathrm{Nd} / \mathrm{NdFeB} / \mathrm{Nd} / \mathrm{Ta}$ films. With $\mathrm{NdFeB}$ layer thickness increasing from $450 \mathrm{~nm}$ to $750 \mathrm{~nm}$, both the in-plane and perpendicular coercivities drastically increase. However, when $\mathrm{NdFeB}$ layer thickness further increases to $900 \mathrm{~nm}$, both the in-plane and perpendicular coercivities slowly decrease. When $\mathrm{NdFeB}$ layer thickness is $750 \mathrm{~nm}$, both the in-plane and perpendicular coercivities reach the maximum, which are $21.2 \mathrm{kOe}$ and $19.5 \mathrm{kOe}$, respectively. It can be interpreted that the strain is minimized at the NdFeB layer of $750 \mathrm{~nm}$, which is favorable for the crystallization of $\mathrm{NdFeB}$.

Figure 5 shows the in-plane and out-of-plane hysteresis loops of $\mathrm{Ta} / \mathrm{Nd} / \mathrm{NdFeB}(750 \mathrm{~nm}) / \mathrm{Nd} / \mathrm{Ta}$ film. As seen in Figure 5, the in-plane and out-of-plane coercivities reach $21.2 \mathrm{kOe}$ and $19.5 \mathrm{kOe}$, respectively. The high remanence ratio of 0.87 can also be noticed in the in-plane hysteresis loop, which is also important for the application of NdFeB film. It is very interesting that the out-of-plane hysteresis loop shows a kink near the original point, implying the existence of uncoupled soft magnetic grains, which becomes more significant while the external field is applied along the outof-plane direction [12]. Moreover, the out-of-plane hysteresis loop shows two stage types of initial magnetization behavior with the first magnetization of high susceptibility followed by the second one of low susceptibility, which also suggests the independent magnetization of the uncoupled soft magnetic grains. Zhao et al. proposed that Fe is very likely to occur in $\mathrm{Nd}_{2} \mathrm{Fe}_{14} \mathrm{~B}$ so that many single-phased materials are in fact the two-phased ones [13].

The micromagnetic model was applied to clarify the coercivity mechanisms in permanent and composite materials. Coercivity is a linear function of $H_{A}$ [14]:

$$
H_{C i}(T)=\alpha H_{A}(T)-N_{\text {eff }} M_{s}(T) .
$$

Here, $H_{A}$ is the anisotropy field, $H_{A}=2 K_{1} / M_{s}$, which is the ideal coercivity for the coherent rotation of magnetically isolated single domain particles. $M_{s}$ is the saturation magnetization. $\alpha$ and $N_{\text {eff }}$ are the microstructure-dependent parameters. The parameter $\alpha$ describes the reduction in the anisotropy field due to the presence of crystallographic defects in the magnetically inhomogeneous region on the grain surface and misalignment of the grains. The parameter $N_{\text {eff }}$ describes the local demagnetization field, which assists nucleation of the reversed domain under the action of the applied inverse field. The temperature dependence of $K_{1}$ is obtained from Durst and Kronmüller [15]. Figure 6 shows 


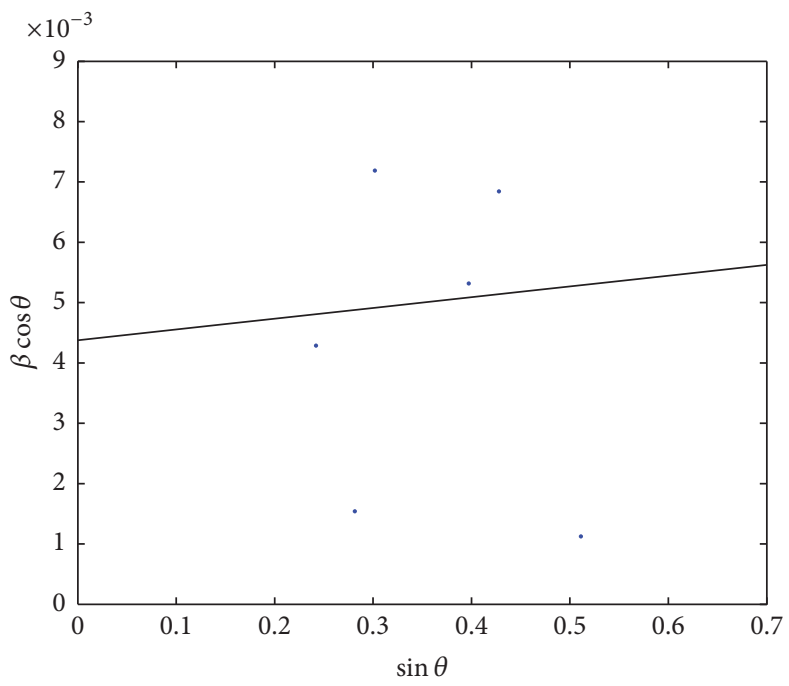

(a)

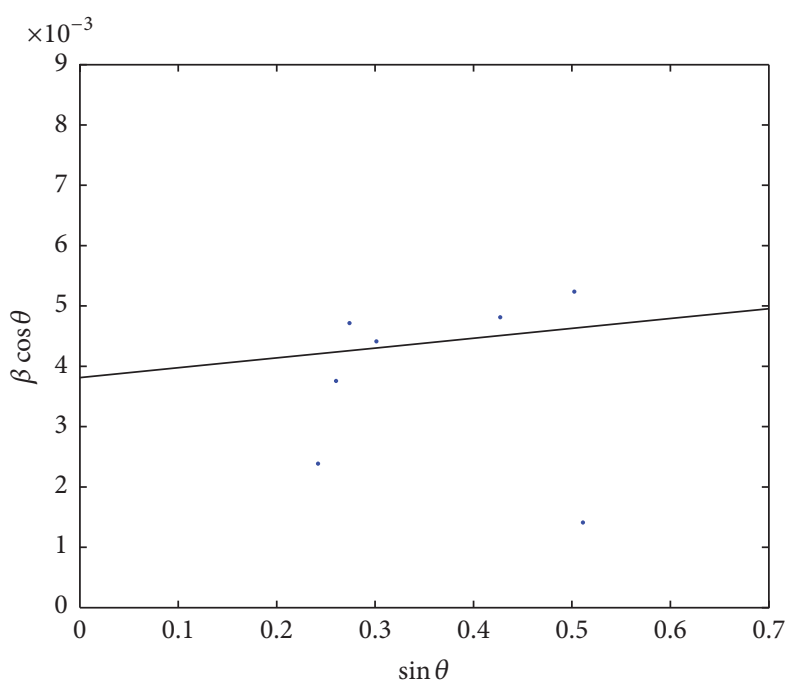

(c)

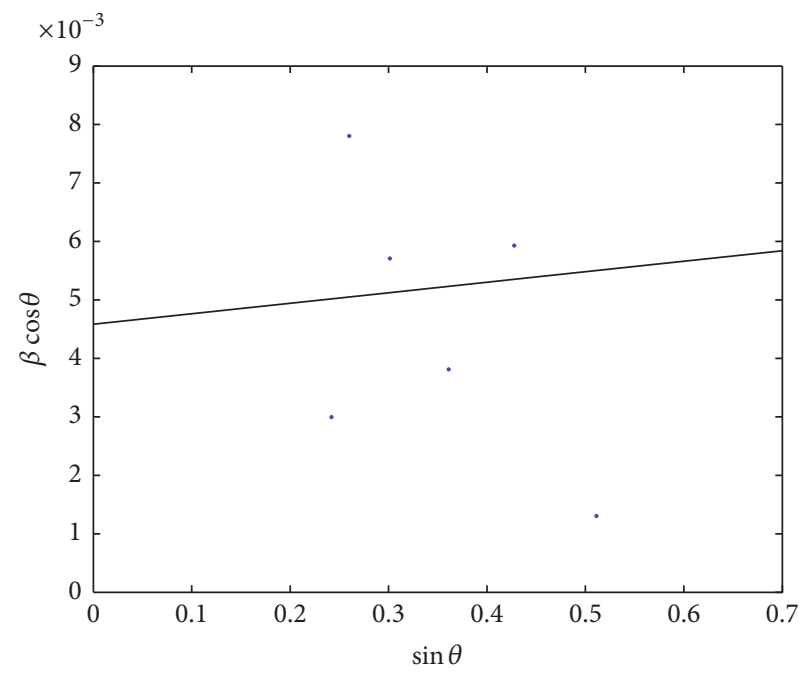

(b)

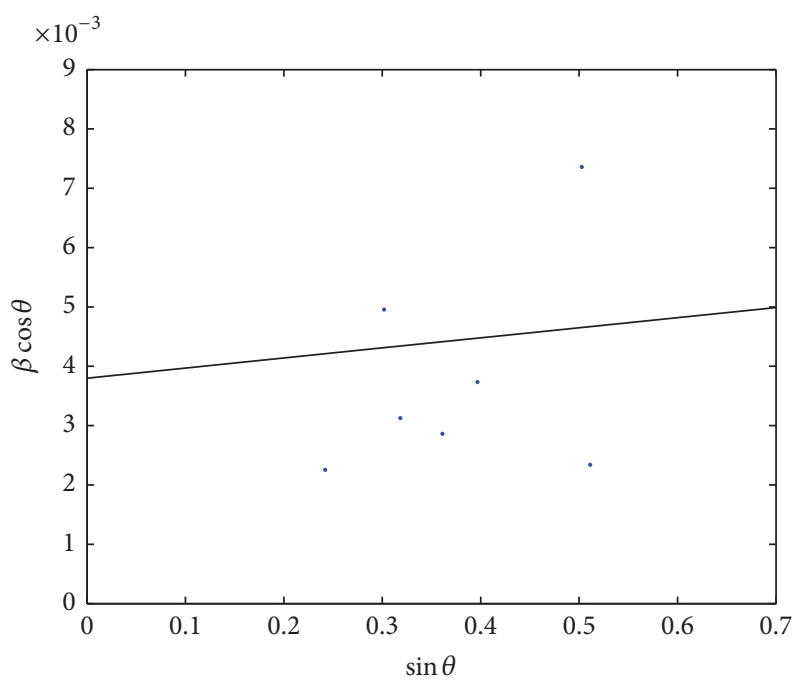

(d)

Figure 2: Plot of $\beta \cos \theta$ versus $\sin \theta$ of Ta/Nd/NdFeB $(x \mathrm{~nm}) / \mathrm{Nd} / \mathrm{Ta}((\mathrm{a}) x=450$; (b) $x=600$; (c) $x=750$; (d) $x=900)$ films.

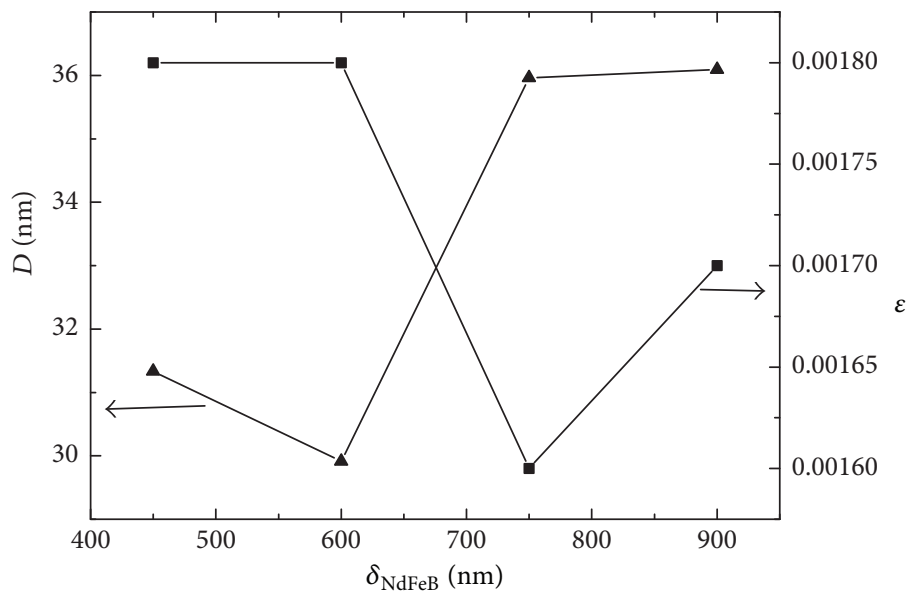

FIGURE 3: Variation of the grain size and strain with $\mathrm{NdFeB}$ layer thickness in $\mathrm{Ta} / \mathrm{Nd} / \mathrm{NdFeB} / \mathrm{Nd} / \mathrm{Ta}$ films. 


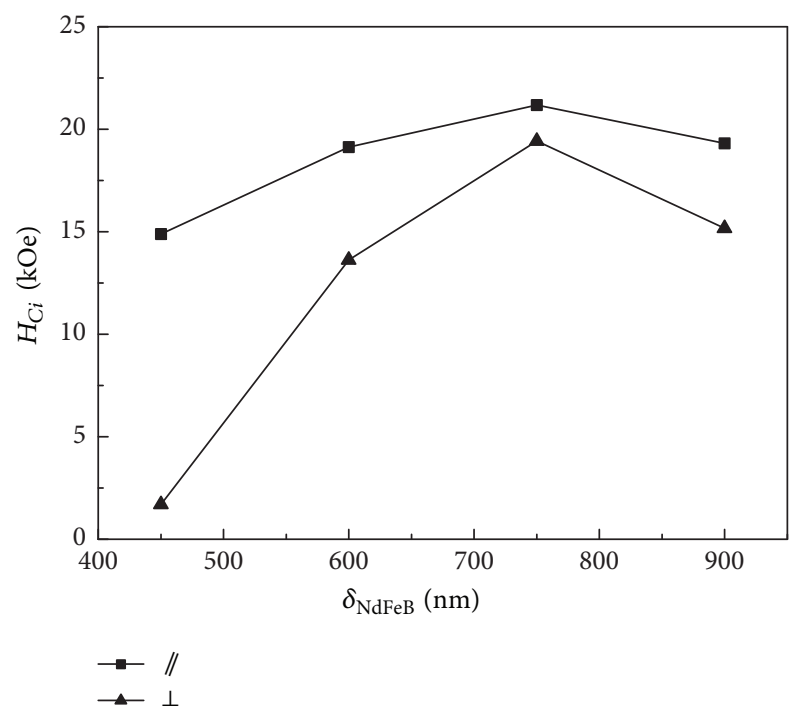

Figure 4: Dependence of the coercivity on the NdFeB layer thickness in $\mathrm{Ta} / \mathrm{Nd} / \mathrm{NdFeB} / \mathrm{Nd} / \mathrm{Ta}$ films.

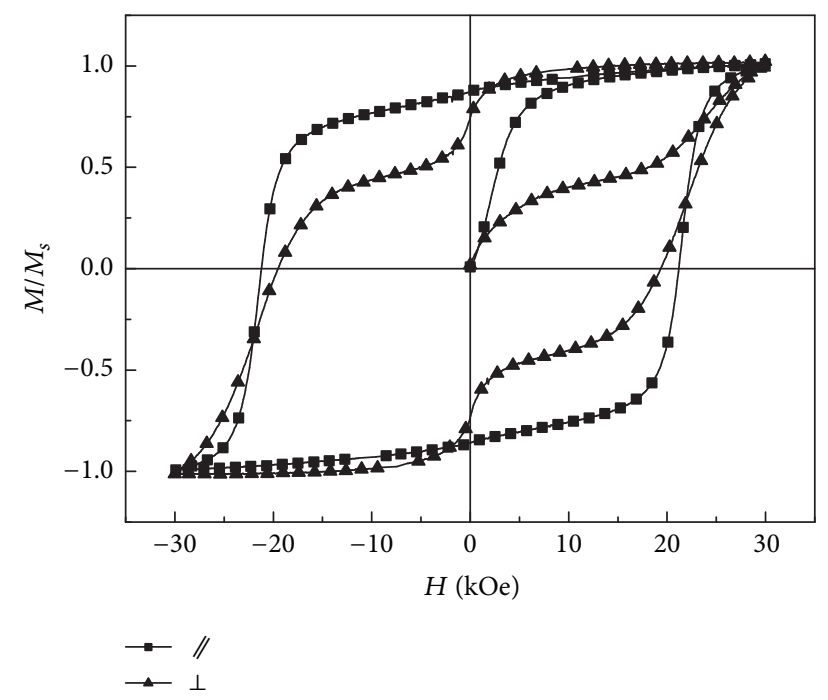

FIgURE 5: Hysteresis loops of Ta/Nd/NdFeB $(750 \mathrm{~nm}) / \mathrm{Nd} / \mathrm{Ta}$ film.

the dependence of $H_{C i} / M_{s}$ on $H_{A} / M_{s}$ for $\mathrm{Ta} / \mathrm{Nd} / \mathrm{NdFeB}$ $(x \mathrm{~nm}) / \mathrm{Nd} / \mathrm{Ta}(x=450,600,750,900)$ films. The micromagnetic parameters $\alpha$ and $N_{\text {eff }}$ were fitted by the least squares method and are shown in Figure 6. It can be noticed that $\alpha$ for $\mathrm{Ta} / \mathrm{Nd} / \mathrm{NdFeB}(750 \mathrm{~nm}) / \mathrm{Nd} / \mathrm{Ta}$ film is 0.257 , which is larger than those of other $\mathrm{Ta} / \mathrm{Nd} / \mathrm{NdFeB} / \mathrm{Nd} / \mathrm{Ta}$ films. It suggests a decrease in the size of the distorted region and/or a considerable release of interfacial misfit at the $\mathrm{NdFeB}$ layer of $750 \mathrm{~nm}$ [16]. Zhao et al. proposed a self-pinning coercivity mechanism, incorporating elements of both initial local nucleation process and subsequent propagation of the domain wall to the main phase $[13,17]$. Such a mechanism was firstly proposed in hard-soft multilayers and then extended to composite and permanent nanomagnets. The defects in the so-called single-phased permanent magnets act as the nucleation and pinning centers, which plays a role similar to the soft phase in hard-soft composite systems. Such

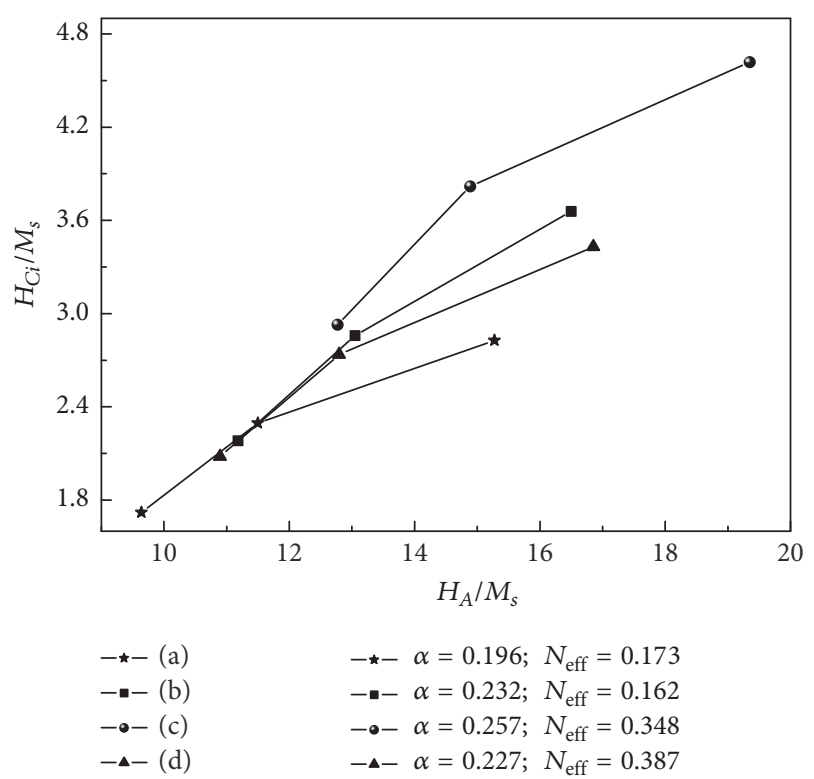

Figure 6: Dependence of $H_{C i} / M_{s}$ on $H_{A} / M_{s}$ for $\mathrm{Ta} / \mathrm{Nd} / \mathrm{NdFeB}$ $(x \mathrm{~nm}) / \mathrm{Nd} / \mathrm{Ta}((\mathrm{a}) x=450$; (b) $x=600$; (c) $x=750$; (d) $x=900)$ films.

self-pinning is attributed to the change of the intrinsic parameters associated with the phase change at the interface. In particular, for sufficiently large soft grains/defects, the pinning field can be expressed as $H_{P}=\alpha H_{K}$, where $H_{K}=$ $2 k / M_{s}$ is the anisotropy field and $\alpha$ depends on the material parameters and micromagnetic structures. The coefficient $\alpha$ decreases as the volume occupation of the soft phase increases. For an exchange-coupled $\mathrm{Nd}_{2} \mathrm{Fe}_{14} \mathrm{~B}-\alpha \mathrm{Fe}$ system with abrupt change of parameters in the interface, $\alpha=0.1$. For the permanent magnets in which small amount of soft grains exists, $\alpha=0.2-0.3$. As is shown in Figure 6 , the $\alpha$ value is between 0.196 and 0.257 , which is consistent with the theoretical value of the permanent magnets, indicating the existence of soft grains. It is accordant with the results concluded from Figure 5.

\section{Conclusions}

In summary, the microstructure and magnetic properties of $\mathrm{Ta} / \mathrm{Nd} / \mathrm{NdFeB} / \mathrm{Nd} / \mathrm{Ta}$ films are strongly dependent on the NdFeB layer thickness. When $\mathrm{NdFeB}$ layer thickness is $750 \mathrm{~nm}$, the strain reaches the minimum value. Meanwhile, the highest in-plane and perpendicular coercivities can be obtained at NdFeB layer thickness of $750 \mathrm{~nm}$, which are, respectively, $21.2 \mathrm{kOe}$ and $19.5 \mathrm{kOe}$, because the strain is minimized. The high remanence ratio of 0.87 can also be achieved in $\mathrm{Ta} / \mathrm{Nd} / \mathrm{NdFeB}(750 \mathrm{~nm}) / \mathrm{Nd} / \mathrm{Ta}$ film. Altogether, the results suggest that $\mathrm{Ta} / \mathrm{Nd} / \mathrm{NdFeB} / \mathrm{Nd} / \mathrm{Ta}$ film may have a significant potential as a magnetic material with excellent performance.

\section{Competing Interests}

The authors declare that there is no conflict of interests regarding the publication of this paper. 


\section{Acknowledgments}

This work was supported by the National Natural Science Foundation of China (no. 51305290), the Higher Education Technical Innovation Project of Shanxi Province, China (no. 2013133), the Fund Program for the Scientific Activities of Selected Returned Overseas Professionals of Shanxi Province, China (no. 2015003), the Research Project Supported by Shanxi Scholarship Council, China (no. 2013-098), and the Graduate Student Joint Training Project of Shanxi Province, China (no. 2016JD36).

\section{References}

[1] J. J. Croat, J. F. Herbst, R. W. Lee, and F. E. Pinkerton, "Pr-Fe and Nd-Fe-based materials: a new class of high-performance permanent magnets (invited)," Journal of Applied Physics, vol. 55, no. 6, pp. 2078-2082, 1984.

[2] Y. Kaneko, K. Tokuhara, and N. Ishigaki, "Research on high performance Nd-Fe-B sintered magnets," Vacuum, vol. 47, no. 6-8, pp. 907-910, 1996.

[3] M. Nakano, R. Katoh, H. Fukunaga, S. Tutumi, and F. Yamashita, "Fabrication of Nd-Fe-B Thick-Film Magnets by High-Speed PLD Method," IEEE Transactions on Magnetics, vol. 39, no. 5, pp. 2863-2865, 2003.

[4] W. Szmaja, J. Grobelny, M. Cichomski, and K. Makita, "Application of MFM for studying Nd-Fe-B magnets," Vacuum, vol. 74, no. 2, pp. 297-300, 2004.

[5] C. Constantinescu, N. Scarisoreanu, A. Moldovan, M. Dinescu, L. Petrescu, and G. Epureanu, "Thin films of NdFeB deposited by PLD technique," Applied Surface Science, vol. 253, no. 19, pp. 8192-8196, 2007.

[6] S. Sinnema, R. J. Radwanski, J. J. M. Franse, D. B. de Mooij, and K. H. J. Buschow, "Magnetic properties of ternary rareearth compounds of the type R2Fe14B," Journal of Magnetism and Magnetic Materials, vol. 44, no. 3, pp. 333-341, 1984.

[7] T. Fukagawa, T. Ohkubo, S. Hirosawa, and K. Hono, "Nanosized disorders in hard magnetic grains and their influence on magnetization reversal at artificial $\mathrm{Nd} / \mathrm{Nd}_{2} \mathrm{Fe}_{14} \mathrm{~B}$ interfaces," Journal of Magnetism and Magnetic Materials, vol. 322, no. 21, pp. 3346-3350, 2010.

[8] M.-J. Kim, Y. Li, Y.-B. Kim et al., "Magnetic properties of NdFeB thin film obtained by diffusion annealing," IEEE Transactions on Magnetics, vol. 36, no. 5, pp. 3370-3372, 2000.

[9] D. Li, S. Suzuki, T. Horikawa, M. Itoh, and K.-I. Machida, "Grain boundary phase formation and magnetic properties of $\mathrm{NdFeB} / \mathrm{Nd}$ multilayered films," Japanese Journal of Applied Physics, vol. 48, no. 3, p. 033002, 2009.

[10] R. Yogamalar, R. Srinivasan, A. Vinu, K. Ariga, and A. C. Bose, "X-ray peak broadening analysis in $\mathrm{ZnO}$ nanoparticles," Solid State Communications, vol. 149, no. 43-44, pp. 1919-1923, 2009.

[11] W. H. Hall, "X-ray line broadening in metals," Proceedings of the Physical Society A, vol. 62, no. 11, pp. 741-743, 1949.

[12] N. Tian, Y. F. Li, F. Hong, and C. Y. You, "Fabrication of high coercive $\mathrm{Nd}-\mathrm{Fe}-\mathrm{B}$ based thin films through annealing $\mathrm{Nd}-\mathrm{Fe}-$ B/Nd-Fe multilayers," Physica B: Condensed Matter, vol. 477, pp. 129-132, 2015.

[13] G. P. Zhao, H. W. Zhang, Y. P. Feng, C. Yang, and C. W. Huang, "Nucleation or pinning: dominant coercivity mechanism in exchange-coupled permanent/composite magnets," Computational Materials Science, vol. 44, no. 1, pp. 122-126, 2008.
[14] H. Kronmuller, "The nucleation fields of uniaxial ferromagnetic crystals," Physica Status Solidi (B), vol. 130, no. 1, pp. 197-203, 1985.

[15] K.-D. Durst and H. Kronmüller, "Determination of intrinsic magnetic material parameters of $\mathrm{Nd}_{2} \mathrm{Fe}_{14} \mathrm{~B}$ from magnetic measurements of sintered $\mathrm{Nd}_{15} \mathrm{Fe}_{77} \mathrm{~B}_{8}$ magnets," Journal of Magnetism and Magnetic Materials, vol. 59, no. 1-2, pp. 86-94, 1986.

[16] W. B. Cui, Y. K. Takahashi, and K. Hono, "Microstructure optimization to achieve high coercivity in anisotropic Nd-Fe-B thin films," Acta Materialia, vol. 59, no. 20, pp. 7768-7775, 2011.

[17] G. P. Zhao, L. Chen, C. W. Huang, N. L. Guo, and Y. P. Feng, "Micromagnetic calculation of hysteresis loops in exchangecoupled nanolayers," Solid State Communications, vol. 150, no. 31-32, pp. 1486-1488, 2010. 

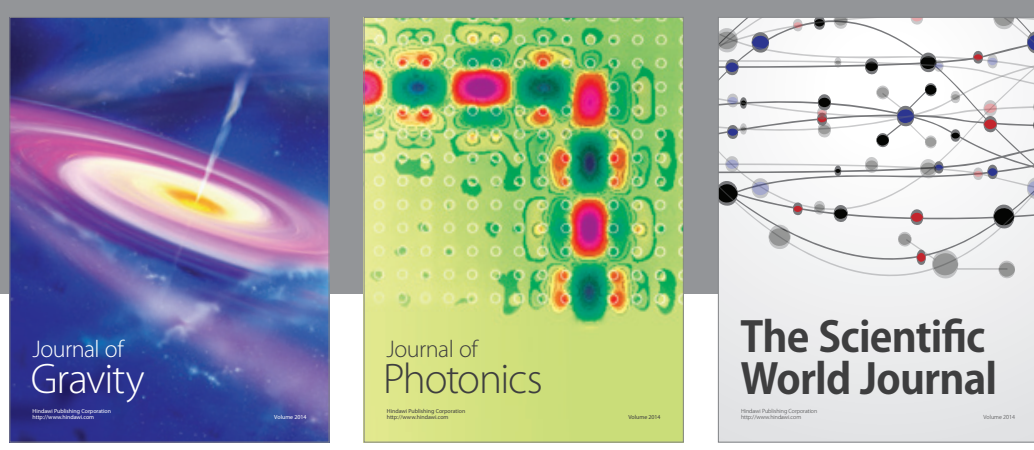

The Scientific World Journal
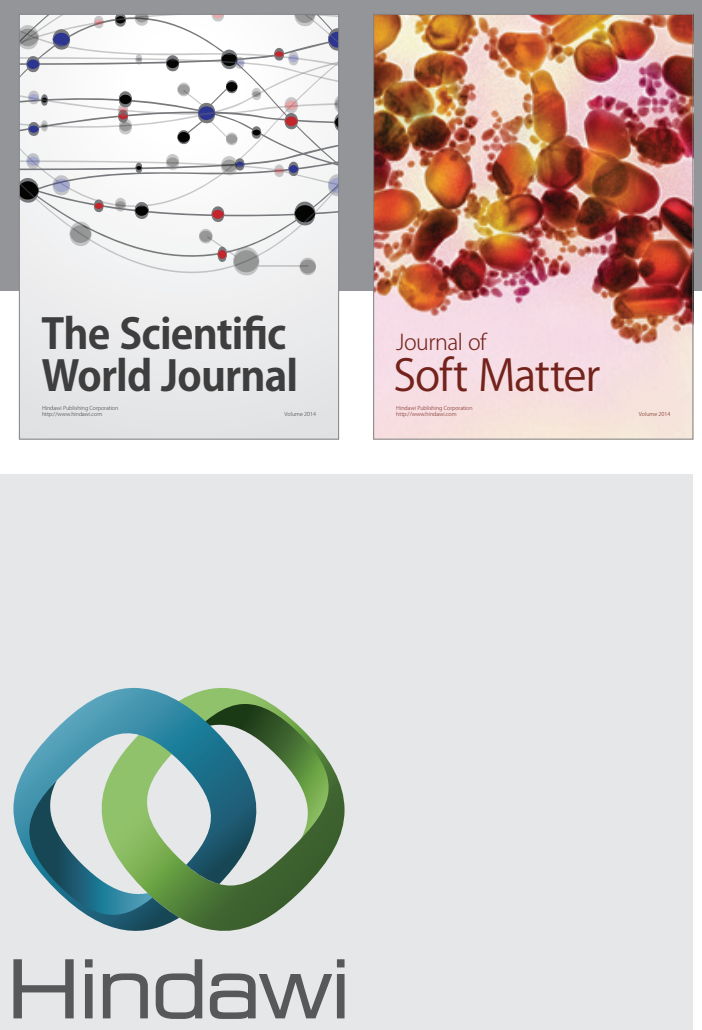

Submit your manuscripts at

https://www.hindawi.com
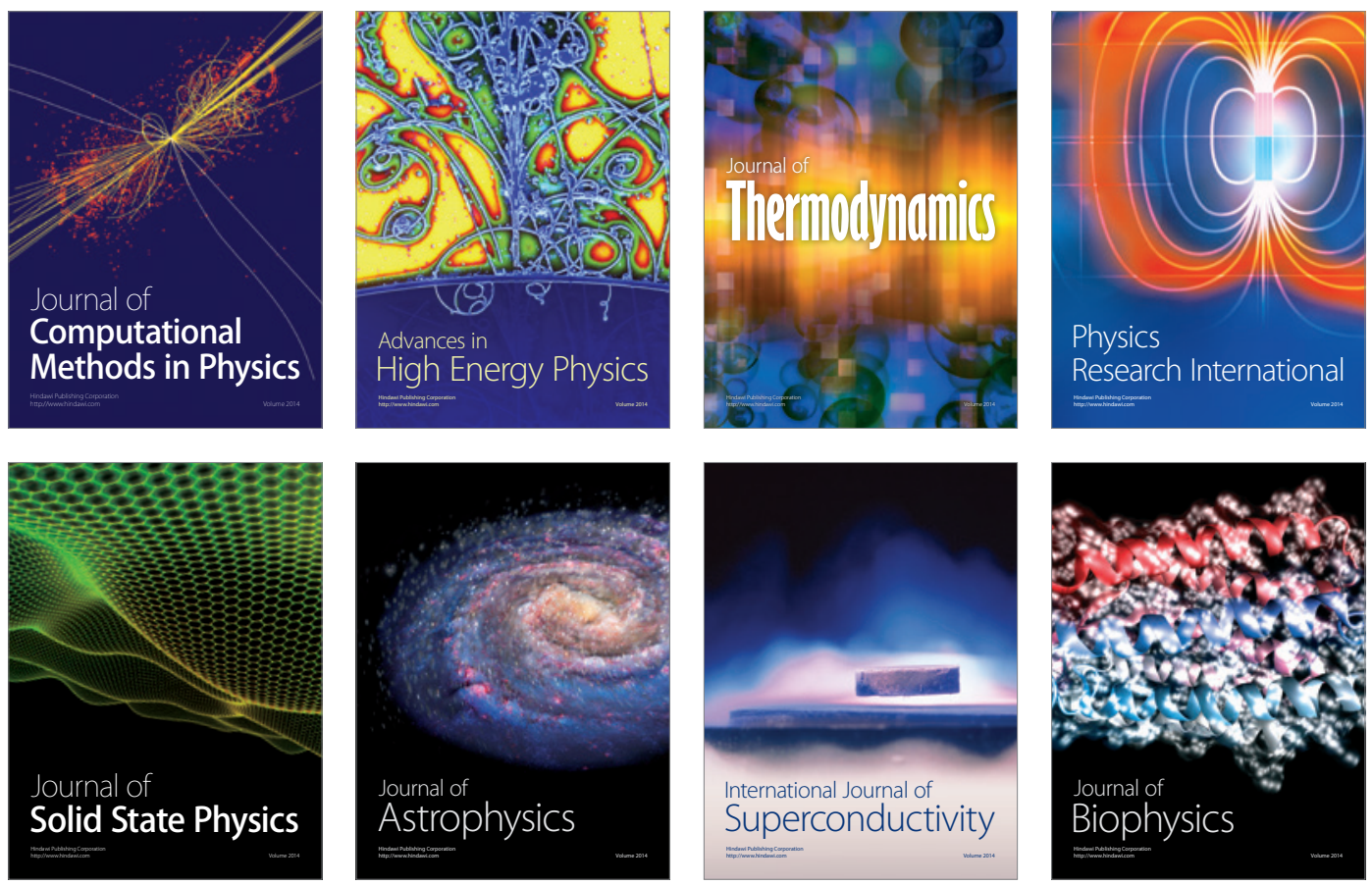
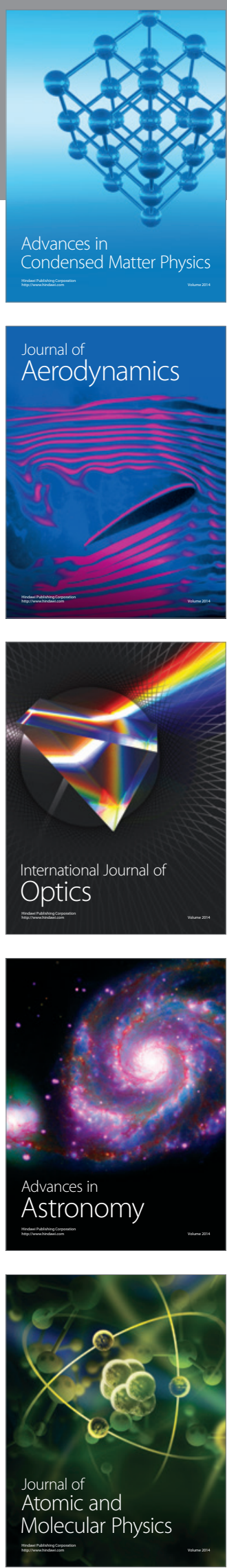